\title{
EXPLORING CONSTRUCTED VISUAL REPRESENTATION OF SELF: A SEMIOTIC ANALYSIS OF FACEBOOK SELFIES
}

\author{
Faiza Khalid \\ Lecturer, National University of Modern Languages, Islamabad \\ fkhalid@numl.edu.pk
}

\author{
Amna Zulfiqar \\ Assistant Professor in National University of Modern Languages, Islamabad. \\ amzulfiqar@numl.edu.pk
}

\author{
Adnan Ramzan \\ Lecturer, National University of Modern Languages, Islamabad \\ aramzan@numl.edu.pk
}

\begin{abstract}
Development of various social media platforms allow people to create and share self-representation. Among all platforms Facebook is the most popular for constructing visual self-representation through selfies. Therefore, the current study aims to investigate the constructed visual representation of self (signs and symbols) through selfies posted by Facebook users. Semiotic analysis is used to analyze a sample of twenty selfies from five profiles by setting different indicators. Self-awareness, look at me, here I am, what am I wearing and look at this are some of the most significant indicators observed during the analysis. Results indicate that for self-portrayal Facebook users apply different signs and symbols like stretch arms, tilt of head, etc. It is concluded that representation of self through selfies increase the feelings of self-awareness and allows the person to live the time with others on their facebook profiles.
\end{abstract}

Keywords: Selfie, Visual Representation of self, Facebook, semiotic analysis

\section{INTRODUCTION}

We are living in an era of selfie (Saltz, 2014). Selfie, as the name suggests, is derived from self and also depicts the self (Salomon \& Brown, 2017). Technologically, it is a fast self-portrait, captured through Smartphone's front camera and instantaneously disseminated and extolled into a network (Warfield, 2015). It is an instant visual communication of our existing physical presence and what we were doing at time and how we are imagining ourselves and for those for whom we believe they shall be watching (Ozansoy Sangkaya, 2016). Selfies have evolved the meanings of everything everywhere. Whether it is social interaction, body language, self-awareness, privacy, and humor, altering temporality, irony and public behavior, it has now undoubtedly evolved as a visual genre, a new kind of self-portraiture formally unique from all others in history (Shah, 2015).

Selfies follow a unique structural autonomy as a very big arrangement for art. Selfies are usually casual and fast, and the primary purpose is to be seen and observed by other people and among them most of them may be unknown on social networks (Tuzovic, 2014). Therefore, selfie can be studied as an object and practice of interdisciplinary interest. Selfie has certain theoretical reflections on how the selfie can be interpreted as an important form of commodity and consumer behavior. The use of selfie with a strategy says that it's a new trend in advertising. It carries along persuasion, information and symbols of social prevalence.

From old times till date, the subject of representation has been an interesting area of research for people of all ages. In the olden times, people used to draw different shapes to express the pictures of their mind, eventually written language used to represent the complexity of the mind. Due to rapid transformation of traditional media to social media, pictures have replaced words in order to represent the thoughts (Bryant, 2021). Therefore, (Lehner, 2021) said that social media has changed the dynamics of the world; our classrooms and even our bedrooms have become global. Personal details are liked and shared by each one of us. To further explore the dynamics of social media platforms it is 
important to explain the term of representation which is connected with the pictures people post on social media platforms. The term representation signifies an object, an indication of how someone can be seen. Currently, people's selfie, tweet or status on social media are considered as representation (Peraica, 2017; Busetta \& Coladonato, 2015; Christel, 2015).

For the purpose of self-representation people use variety of methods and techniques and keep on exploring the updated version of self-representation (Steinsbek, Wichstrom,Steseng, Nesi, Hygen \& Skalicka, 2021). In the recent past, our grandparents use to keep diaries (Nandi, 2021) for their selfdescription, hidden in their drawers hardly letting anyone to read. And it was usually after the death of someone that their diaries were opened in order to explore the details about the person's personality (Vickery, 2021). In contrast, today's generation has tendency to post selfies on social media to keep their friends updated about day to day/min to min activities. People post their selfies on various social media platforms like Instagram, snap chat, Facebook, Tumblr posts and Twitter's tweets. With social media, even common people share their self-representation to the audience at large which is considered as new form of visual representation. Thus, the current study explored the visual representation of self through the selfies posted by Facebook users. Facebook is considered as one of the social media platform where oftenly people post their selfies by using diverse signs and symbols of visual self-representation. Therefore, the study incorporated semiotic analysis for analyzing the signs and symbols in the selfies posted on Facebook (Qutub, 2021)

\section{Research Question}

How the selfies portray the constructed visual representation of self on Facebook profiles?

\section{REVIEW OF LITERATURE}

Self-Representation is of great importance since a lot of time in the past and specifically a topic of people's interest (Enli \& Syvertsen, 2007). The dynamics of self-representation have changed drastically including the foundations of societies which were interpersonal, but now the platforms are transformed into unimaginable outcomes particularly for online sharing and self-portrayal. Consequently, selfies are now considered as a new way for self-representation on social networking sites. It is also notable that introductions are now made on social media by using selfies (Döring, Reif, \& Poeschl, 2016). Malik, Dhir, \& Nieminen, (2016), were of the view that people post selfies on the internet for seeking affection, disclosure, attention, pastime hobby, information sharing and fulfilling the motives socially. The purpose of such type of self-representation on the facebook involves communication, entertainment, self-preservation (Holiday, Lewis, Nielsen, Anderson, \& Elinzano, 2016), self-expression, escapism, peeking and social interaction (Lee, Lee, Moon, \& Sung, 2015); communication, entertainment, attention seeking and archiving.

The phenomenon of selfie is of huge interest for people now-a-days (Halpern, Katz \& Carril, 2017). The efforts were made to see the deep relationship between the selfie posting and the level of satisfaction related to it. Selfie helps in a lot of roles, but currently the major focus on selfpresentation role has been assessed, as it is said it serves as a catalyst for the presentation of self and it denotes the generation in the context of 'Me' and the central point of the communication is the self (Paris \& Pietschnig, 2015). These selfies are user generated self-representations and possibly draws a progressively adaptable image of the user or the gender rather than producing some gender stereotypical representations. According to Pounders et al., (2017) all of the social media tools can be used as a platform for communication by students. In this way they can build relationships online and express themselves and social culture may be transformed by the selfie trend (Sung et al., 2016). In one of the research findings it was taken into the account that the edited self-representation is an effort to upgrade the sense of self (Chua \& Chang, 2016).

Locating the identity of self on social media is of serious interest for many scholars (Hall, 2014). Since a variety of identities exist on social media platforms ranging from personal, physical, psychological to social and technological (Bostrom \& Sandberg, 2011). It is also associated with the wellbeing of a person if he is living his true identity. It evokes serious outcomes like strong reactions if the identity is at stake or threatened. Being a single person we are playing different identities at a single time. These multiple identities are an essential part of our wellbeing and living (Horowitz, 2012). We shift between different identities to form certain social identities in a variety of contexts (jobs, family, friends, etc). For example, if you are a mother, you are also a daughter, sister, wife, 
friend, student, teacher, etc. Similarly, like this we have online identities that we make on social media. These online identities are now a day's very important part of self. These identities can refer not only to give us access to multiple resources but they also help us in linking to different social identities (Mendelson, \& Papacharissi, 2010). Technology has a direct link with our online identities, it is technology that provides the platform for social networking. It is technology that affects the functioning of our identities, and this can have a very important effect on the individual and the society (Kim, Lee, Sung, \& Choi, 2016). The online identities are rapidly increasing in this modern era, especially on Facebook. The usage of Facebook for communicating through identities is very common in this decade.

People use various platforms which help in fostering integration and identity sharing. These platforms are basically social networking sites commonly known as SNS. Most common of all is Facebook that has a huge collection of portrayals and photos. Carey (1975) conducted research on photos and collected photos of college students and analyzed the symbols. The major commonality among the photos were the poses or the doings that seemed identical irrespective of the location (Vivienne \& Burgess, 2013). These representations on Facebook are not just the photos taken from your own phone but also some are tagged photos of a person. These photos were taken at different times, some narrate unusual stories at various points of time. Photos also present stories or intentional representation of a social group and life. These photographs provide a platform for students to speak to each other and also live each other's life visually (Warfield, 2015). These photographs prove a genuine college experience filled with friends and the rituals of college life, eating, drinking, sports and closeness of a peer group. These photos serve the purpose of making us feel more independent in different stages of life (Horowitz, 2012).

Photo sharing on Facebook is a source of entertainment for people. It is a way of preserving memories and also indulging other people enjoying your moments. Most of the people who are sharing their photos on social media are either teenagers, college and university students or some from middle age. Selfie as a source of self-representation is very common in teenagers and their counterparts. Along with college and university students, middle-age people also represent themselves on social media. Therefore, the present study revolves around the visual representation of self through selfie-posted on Facebook profiles. This study is one of its kind in Pakistani settings because over a period of time selfies have increased social sensitivity which has minimized self-esteem. While going through the literature around the world the researchers analyzed that there is a dire need to conduct more studies in the context of Pakistan. This study would be a value edition for upcoming researchers who want to conduct research in this area of research.

\section{METHODOLOGY}

The current paper revolves around the visual representation of self through selfie on Facebook profiles. Facebook is one of the most widely used phenomena for sharing photographs and creating online identity. Therefore, the paper revolves around the indicators and symbols depicted in the selfies posted by Facebook users. Facebook has been operationalized as the universe where the selfies were posted and were analyzed from this universe. The study incorporated qualitative data analysis for analyzing selfies using semiotic analysis. According to (Leone, 2018), semiotic analysis has been used in the analysis of photographs. Semiotic Analysis treats the picture (Selfie) in its complete form as totality-marking the patterned relationships in its content, connecting these two parallels and contrasting structures in other pictures, and relating both to the written narratives that accompany them (Barthes 1977, 1982; Woollacott 1982).

The researcher employed the method of semiotic analysis by exploring signs and symbols within the selfies. Furthermore, purposive sampling is used for filtering the relevant selfies as per the indicators mentioned in Table\#1. After analyzing 500 profiles, 20 Facebook profiles were selected on basis of indicators mentioned in Table\#1, then they were shortlisted to 5 because of the absence of selfies posted by users. The sample profiles were diverse in nature because they were selected on the basis of demographics and physiography. After analyzing 5 profiles, 100 selfies were selected from each profile and 20 Selfies were selected for the analysis. These 20 selfies were selected against five indicators. So, each indicator has four selfies from each profile for analysis. The Table below shows indicators for Self-representation and Selfie 
Table No. 1 Indicators for Self and Selfie Analysis

\begin{tabular}{|c|c|}
\hline Self-Representation & Indicators for Selfie \\
\hline Self-awareness & Duckface \\
\hline Look at me & Outstretched arm \\
\hline Here I am & Tilt of Head \\
\hline What am I wearing & Position of Arm \\
\hline Look at this & Eye Squint \\
\hline
\end{tabular}

Table No. 2 Explanation of the indicator in Table\#1

\begin{tabular}{|c|c|c|c|}
\hline $\begin{array}{c}\text { Self- } \\
\text { Representation }\end{array}$ & Meaning & $\begin{array}{l}\text { Indicators } \\
\text { for Selfie }\end{array}$ & $\begin{array}{c}\text { Explanation for the Selfie } \\
\text { Indicators }\end{array}$ \\
\hline Self-awareness & $\begin{array}{c}\text { Self-awareness refers to a } \\
\text { phenomenon which explains } \\
\text { how someone is obsessed with } \\
\text { him/herself. He/she feels that I } \\
\text { am looking very beautiful and } \\
\text { attractive }\end{array}$ & Duckface & $\begin{array}{l}\text { Duckface is an exaggerated } \\
\text { expression of lips, a form of } \\
\text { pouting in which lips are more } \\
\text { outward and circular. }\end{array}$ \\
\hline Look at me & $\begin{array}{l}\text { Looking at me provokes the } \\
\text { feeling in the viewer that I } \\
\text { have done something } \\
\text { interesting or I have a story to } \\
\text { narrate. }\end{array}$ & $\begin{array}{l}\text { Outstretched } \\
\text { arm }\end{array}$ & $\begin{array}{l}\text { Outstretched arm is defined as a } \\
\text { situation that is used for posing } \\
\text { a photograph. It is made in a } \\
\text { manner when you want to give } \\
\text { an impression to others i.e., to } \\
\text { look at you. }\end{array}$ \\
\hline Here I am & $\begin{array}{l}\text { Here I signify the phenomenon } \\
\text { of virtual storytelling/ tourism } \\
\text { via selfies. When we share } \\
\text { each and every location/ aspect } \\
\text { of our surroundings on } \\
\text { facebook. }\end{array}$ & Tilt of Head & $\begin{array}{l}\text { Tilt of Head is a position when } \\
\text { you are trying to hide fats of the } \\
\text { face and in selfies this position } \\
\text { is used to portray the location } \\
\text { that is around you. }\end{array}$ \\
\hline $\begin{array}{l}\text { What am I } \\
\text { wearing }\end{array}$ & $\begin{array}{l}\text { What I am wearing is denoting } \\
\text { the fact that the person wants } \\
\text { the audience to note what they } \\
\text { are wearing, it can be a new } \\
\text { dress, glasses, jewelry, etc. }\end{array}$ & $\begin{array}{l}\text { Position of } \\
\text { Arm }\end{array}$ & $\begin{array}{l}\text { The position of Arm in the } \\
\text { picture determines that the } \\
\text { person is keeping the phone at a } \\
\text { distance and trying to take } \\
\text { bigger selfies and keeping a } \\
\text { focus on dress. }\end{array}$ \\
\hline Look at this & $\begin{array}{l}\text { Looking at this determines the } \\
\text { phenomenon of pride in one's } \\
\text { self. }\end{array}$ & Eye Squint & $\begin{array}{l}\text { When someone is showing an } \\
\text { eye squint in the picture which } \\
\text { states 'want to live that } \\
\text { moment', excitement with the } \\
\text { audience. }\end{array}$ \\
\hline
\end{tabular}

\section{FINDINGS}

Profile \# 1. Abeer Kiani. A young energetic entrepreneur running her own restaurant, Abeer is fond of taking selfies. In the analysis of her selfies, it was analyzed that all the selfies have a constructed self-representation like Look at me, here I am, see what I am wearing, and look at this happening. Basically, these selfies are serving the purpose of storytelling, self-love and feelings of self-awareness are at the peak. The elements of techniques like outstretched arm, Tilt of Head, Position of Arm, Eye Squint and Duck face all are seen in the Selfies of Abeer. These all indicators depict that self is created virtually by manipulations and it is just a representation of what the person wants to show, not a depiction of reality. A sense of achievement is prevailing in selfies. 
Profile \# 2, Mariya Rajput. Mariya is a young ambitious girl coming from a less wealthy background. She is seen struggling with life in her selfies too. She is an anchor person and a cricket lover. Her Selfies carry a visual sense of achievement as if she is telling everyone to look at me and look at this. The sense of self awareness is also seen in the selfies where she feels elevated in achieving her dreams and moving ahead in her career. Looking at the technical construction of the selfies, in her selfies all the visual elements like an outstretched arm, tilt of head, position of arm, eye squint and Duckface are observed.

Profile \# 3 is Omar Mahmood. Omar is an American Pakistani and by profession he is an engineer. $\mathrm{He}$ is very fond of travelling. In all her photos there is a continuous sense of look at me and look at this is seen. He enhances the look at me by taking photographs with the people around the world. For Omar What I am wearing is not specifically seen in the selfies. But the other indicators like selfawareness, look at me, here I am and look at this were observed in his selfies oftenly. This shows his continuous relation to self and he is trying to overshadow other aspects through his presence of self as an identity in the selfies. Tilt of head, outstretched arm, eye squint, position of head and duck face were the indicators in his selfies.

Profile \# 4 is of Muhammad Waqas. M Waqas is a recent graduate of Mass communication. He is looking for a good job in the market. Most of his selfies are with his friends enjoying different times of youth hood. Most of the selfies are in a very serious mood or just taken randomly. The indicator of self-awareness was not present in his selfies. Few of his selfies showed indicator of look at me, here I am or look at this. The techniques of taking selfies were also observed in his selfies. Outstretched arms, tilt of head, position of arm and eye squint was also observed in his selfies. There was no picture with a Duckface.

Profile \# $\mathbf{5}$ is Noor ul Ain Khan, she is working in a seven-star hotel. She is a fun loving and outgoing personality. The continuous sense that prevails in all her selfies is that look at me and look at this. She is in a continuous urge to make others see how she is enjoying every moment of her life. Her selfies were mostly related to her friends' i.e, friends' view her wherever she goes. Her sense of self seemed really high. Indicators like an outstretched arm, tilt of head, position of arm, eye squint and Duckface were present in her selfies.

\section{DISCUSSION}

The current study analyzed five profiles of facebook users. All the five profiles were carefully chosen because of demographics. Self-awareness refers to a phenomenon which explains how someone is obsessed with him/herself. He/she feels that I am looking very beautiful and attractive. Its visual representation is constructed by a duckface. Looking at me provokes the feeling in the viewer that I have done something interesting, or I have a story to narrate. Outstretched arm constructs this visually. Here I am signifying the phenomenon of virtual storytelling/ tourism via selfies. When we share each and every location/ aspect of our surroundings on facebook. The position is denoted by the tilt of head. What I am wearing is denoting the fact that the person wants the audience to note what they are wearing, it can be a new dress, glasses, jewelry, etc. Its visual construction is denoted by the position of Arm. Looking at this determines the phenomenon of pride in oneself. When someone is showing an eye squint in the picture which states, 'want to live that moment', excitement with the audience.

The first subject, Abeer Kiani is a beautiful young girl. Besides being young and beautiful, she is energetic and passionate about her career too. And she loves to stay connected with her friends and online community, she takes pictures and selfies wherever she goes. Her selfie analysis shows that she is in love with herself, she enjoys every moment of her life, she wants to show it to the world when she is wearing a good/new dress. She has constructed a very unique and responsible self on her Facebook profile.

The second subject is Mariya Rajput, who is young, unmarried and a very ambitious girl with a humble background. Her pictures, selfies and statuses show a lot of struggles in her life which she keeps on sharing with her Facebook friends and family. She is a girl with big dreams, a cricket lover, sports reporter and an anchor. After analyzing her selfies, it is assumed that she will be a big star one day, as she is followed and appreciated by hundreds of people on Facebook. Her photos show that she keeps on telling the people to look at her, she wants to show what she is wearing and to share her travelling details through symbols of here I am. 
The third subject of the study is an American Pakistani Engineer. He works at a petrol pump. Omar is very fond of travelling around the world and his back-and-forth travelling was reflected in his photos. His selfies showed that he is a very happy-go-lucky person with a focus of living and enjoying everyday life experiences. He takes pride in being a desi American and proudly shares his village pictures. He also seems to be patriotic for his parent country by the pictures he shared online. He is not much into buying and wearing new clothes and loves to remain simple so the indicators of what I am wearing is not found in his selfies. All other indicators such as tilt of head, eye squint and duck face were observed in his selfies.

Mohammad Waqas has a serious personality, and he is a recent graduate of Mass communication from National University of Modern Languages. After looking at his selfies shared online, we understand himself as a seeker. He is seeking new things in life. He is also in search of a job within and outside the country. His selfie expression appears to be serious and dull. His selfies were random and purposeful. His sense of self-awareness seems missing from his selfies, it seems as if he is concealing himself. But still with all the seriousness his photographs were still inviting a message of look at me, and some of them depicted his travels. Duck Face was not depicted in his selfies. His self-representation seems serious, work oriented yet social.

Noor ul Ain Khan, the fifth subject of the analysis is a creative artist, fun-loving and outgoing personality. She likes to share her success and achievements online. She is working as a PR officer in a seven-star hotel. It was observed from her Facebook photos that since she is on job she is well travelled; she is dressed up well and she eats good food every day. Her construction of identity is about moving forward with achievements in the ladder of life, she send a very positive energy through her selfies and keeps her followers entertained. She wants to stay interactive all the time with her friends and family. The representation of self that she has kept online shows high standards for her life and her self-esteem is well polished.

\section{CONCLUSION}

It is concluded that all the five Facebook users posted a great number of selfies which clearly indicate diverse ways of visual self-representation. The kind of self-presentation portrayed by five facebook users shows that it is constructed, and representation is tilted. The research question of this research was how the selfies portrayed the constructed visual representation of the self on facebook profiles? To answer this question certain indicators were made that are basically related to self-representation. The indicators are mentioned in Table \#1. It was concluded on the findings that were collected on the basis of these indicators that the people wanted to create a constructed visual representation of facebook. This practice is used to show the world the extended version of the self. People make certain defined poses to portrays various self-contained that are explained in the Table \# 2. The finding clearly stated that people who are posting selfies on facebook are obsessed with themselves, they have heightened self-awareness and they want to live the moments of their everyday life with the public around them. It is apparent from the findings that the self-representation in everyday life before going into the presence of others an individual would try to control his impression for the receivers of his situation. The visual self-representation can be intentional or unintentional forms of self-concept and a part of constructed visual self-representation. This is happening in all walks of life where people are creating a constructed self-image for social approval. And facebook is playing a great role and providing a platform for these kinds of presentations and representations.

\section{REFERENCES}

Bevins, C. (2014). Get Schooled: A Visual Social Semiotic Analysis of Target's Branding using Instagram (Order No. 1556748). Available from ProQuest Dissertations \& Theses Global. (1545865136). https://www.proquest.com/dissertations-theses/get-schooled-visual-socialsemiotic-analysis/docview/1545865136/se-2?accountid=135034

Bryant, L. (2021). Stuart Hall \& Theory of Representation in the Media: Exploring Get Out and Candyman. https://scholarworks.arcadia.edu/showcase/2021/media_communication/3

Busetta, L., \& Coladonato, V. (2015). Introduction be your selfie: Identity, aesthetics and power in digital self-representation. Networking Knowledge: Journal of the MeCCSA Postgraduate Network, 8(6). https://doi.org/10.31165/nk.2015.86 
Christel, M. T. (2015). Presenting My Selfie to the Digital World: Visual Composition for Better Representation. In Essentials of Teaching and Integrating Visual and Media Literacy (pp. 119-145). Springer, Cham. https://doi.org/10.1007/978-3-319-05837-5_6

Chua, T. H. H., \& Chang, L. (2016). Follow me and like my beautiful selfies: Singapore teenage girls' engagement in self-presentation and peer comparison on social media. Computers in Human Behavior, 55, 190-197. https://doi.org/10.1016/j.chb.2015.09.011

Döring, N., Reif, A., \& Poeschl, S. (2016). How gender-stereotypical are selfies? A content analysis and comparison with magazine adverts. Computers in Human Behavior, 55, 955-962. https://doi.org/10.1016/j.chb.2015.10.001

Enli, G. S., \& Thumim, N. (2012). Socializing and self-representation online: exploring Facebook. Observatorio (OBS*), 6(1). https://doi.org/10.15847/obsOBS612012489

Goffman, E. (1949). The presentation of self in everyday life. American Journal of Sociology, 55, 6-7. https://monoskop.org/images/1/19/Goffman_Erving_The_Presentation_of_Self_in_Everyday Life.pdf

Hall, S. (2014). Cultural identity and diaspora. In Diaspora and visual culture (pp. 35-47). Routledge. https://doi.org/10.4324/9781315006161

Halpern, D., Katz, J. E., \& Carril, C. (2017). The online ideal persona vs. the jealousy effect: Two explanations of why selfies are associated with lower-quality romantic relationships. Telematics and Informatics, 34(1), 114-123. https://doi.org/10.1016/j.tele.2016.04.014

Holiday, S., Lewis, M. J., Nielsen, R., Anderson, H. D., \& Elinzano, M. (2016). The selfie study: Archetypes and motivations in modern self-photography. Visual Communication Quarterly, 23(3), 175-187. https://doi.org/10.1080/15551393.2016.1223548

Horowitz, M. J. (2012). Self-identity theory and research methods. Journal of Research Practice, 8(2), 14. http://jrp.icaap.org/index.php/jrp/article/view/296/261

Iqani, M., \& Schroeder, J. E. (2016). \# selfie: digital self-portraits as commodity form and consumption practice. Consumption Markets \& Culture, 19(5), 405-415. https://doi.org/10.1080/10253866.2015.1116784

Joinson, A. N. (2008, April). Looking at, looking up or keeping up with people?: motives and use of facebook. In Proceedings of the SIGCHI conference on Human Factors in Computing Systems (pp. 1027-1036). ACM. https://doi.org/10.1145/1357054.1357213

Kim, E., Lee, J. A., Sung, Y., \& Choi, S. M. (2016). Predicting selfie-posting behavior on social networking sites: An extension of theory of planned behavior. Computers in Human Behavior, 62, 116-123. https://doi.org/10.1016/j.chb.2016.03.078

Lee, E., Lee, J. A., Moon, J. H., \& Sung, Y. (2015). Pictures speak louder than words: Motivations for using Instagram. Cyberpsychology, behavior, and social networking, 18(9), 552-556.

Lehner, A. (2021). Self-Representation in an Expanded Field: From Self-Portraiture to Selfie, Contemporary Art in the Social Media Age. https://doi.org/10.3390/books978-3-03897-5656-12 (registering DOI)

Leone, M. (2018). Semiotics of the Selfie: The Glorification of the Present. Punctum, 4(2): 33-48. DOI: $10.18680 /$ hss.2018.0018

Macnamara, J. R. (2005). Media content analysis: Its uses, benefits and best practice methodology. Asia Pacific Public Relations Journal, 6(1), 1-34. https://search.informit.org/doi/10.3316/ielapa.200705762

Malik, A., Dhir, A., \& Nieminen, M. (2016). Uses and gratifications of digital photo sharing on Facebook. Telematics and Informatics, 33(1), 129-138. https://doi.org/10.1016/j.tele.2015.06.009

McAdams, D. P., \& Cox, K. S. (2010). Self and identity across the life span. The Handbook of LifeSpan Development. John Wiley \& Sons, Ltd https://doi.org/10.1002/9780470880166.hlsd002006

McLeod, S. A. (2008). Self-concept. Retrieved from https://www.simplypsychology.org/selfconcept.html 
Mendelson, A. L., \& Papacharissi, Z. (2010). Look at us: Collective narcissism in college student Facebook photo galleries. In A Networked Self (pp. 259-281). Routledge.

Nandi, M. (2021). Enjoying the Diary: Samuel Pepys and the Transitions of Diary-Writing. In Reading the Early Modern English Diary (pp. 161-186). Palgrave Macmillan, Cham. https://doi.org/10.1007/978-3-030-42327-8_7

Nilsson, M. (2016). 'First, let me take a selfie' - Young adults' self representation on Instagram (Dissertation, Malmö högskola/Kultur och samhälle). Retrieved from http://urn.kb.se/resolve?urn=urn:nbn:se:mau:diva-23368

Oliver, M. B., Raney, A. A., Slater, M. D., Appel, M., Hartmann, T., Bartsch, A., ... \& Vorderer, P. (2018). Self-transcendent media experiences: Taking meaningful media to a higher level. Journal of Communication, 68(2), 380-389. https://doi.org/10.1093/joc/jqx020

Ozansoy Çadırcı, T., \& Sağkaya Güngör, A. (2016). Love my selfie: selfies in managing impressions on social networks. Journal of Marketing Communications, 1-20.

Paris, C. M., \& Pietschnig, J. (2015). 'But first, let me take a selfie': Personality traits as predictors of travel selfie taking and sharing behaviors.Travel and Tourism Research Association: Advancing Tourism $\quad$ Research 1. https://scholarworks.umass.edu/ttra/ttra2015/Academic_Papers_Oral/1

Partarakis, N., Kaplanidi, D., Doulgeraki, P., Karuzaki, E., Petraki, A., Metilli, D., Bartalesi, V., Adami, I., Meghini, C, \& Zabulis, X. (2021). Representation and Presentation of Culinary Tradition as Cultural Heritage. Heritage, 4(2), 612-640. MDPI AG. Retrieved from http://dx.doi.org/10.3390/heritage4020036

Peraica, A. (2017). Culture of the selfie: self-representation in contemporary visual culture. Theory on Demand, (24). Institute of Network Cultures.

Qutub, A. (2021). The selfie production model: Rethinking selfie taking, editing, and posting practices. Cyberpsychology: Journal of Psychosocial Research on Cyberspace, 15(4), Article 4. https://doi.org/10.5817/CP2021-4-4

Rettberg, J. W. (2017). Self-Representation in Social Media. https://www.researchgate.net/profile/JillWalker-Rettberg/publication/305073320 Self--

Representation_in_Social_Media/links/5780cb0808ae9485a43bc855/Self--Representation-in$\underline{\text { Social-Media.pdf }}$

Salomon, I., \& Brown, C. S. (2019). The Selfie Generation: Examining the Relationship Between Social Media Use and Early Adolescent Body Image. The Journal of Early Adolescence, 39(4), 539-560. https://doi.org/10.1177/0272431618770809

Saltz, J. (2014). Art at arm's length: A history of the selfie. New York Magazine, 47(2), 71-75. Source: http://www.vulture.com/2014/01/history-of-the-selfie.html

Steinsbekk, S., Wichstrøm, L., Stenseng, F., Nesi, J., Hygen, B. W., \& Skalická, V. (2021). The impact of social media use on appearance self-esteem from childhood to adolescence-A 3wave community study. Computers in Human Behavior, 114, 106528. https://doi.org/10.1016/j.chb.2020.106528

Sung, Y., Lee, J. A., Kim, E., \& Choi, S. M. (2016). Why we post selfies: Understanding motivations for posting pictures of oneself. Personality and Individual Differences, 97, 260-265. https://doi.org/10.1016/j.paid.2016.03.032

Tuzovic, S. (2014). Selfies-Fad or fortune maker for marketers. https://eprints.qut.edu.au/106415/

Vardeman, C. E. (2017). Me, My Selfie, and I: Personality Traits' Influence on Online Self-Portrait Sharing. California State University, Long Beach. http://pqdtopen.proquest.com/\#viewpdf?dispub=10690904

Vickery, A. (2021). A Self off the Shelf: The Rise of the Pocket Diary in Eighteenth-Century England. Eighteenth-Century Studies, 54(3), 667-686. doi:10.1353/ecs.2021.0044.

Vivienne, S., \& Burgess, J. (2013). The remediation of the personal photograph and the politics of self-representation in digital storytelling. Journal of Material Culture, 18(3), 279-298. https://doi.org/10.1177/1359183513492080 
Warfield, K. (2015). Digital Subjectivities and Selfies: The Model, the Self-conscious Thespian, and the\# realme. International Journal of the Image, 6(2).https://doi.org/10.18848/21548560/CGP/v06i02/44167

Yee, N., \& Bailenson, J. (2007). The Proteus effect: The effect of transformed self-representation on behavior. Human communication

https://doi.org/10.1177/0093650208330254

271-290. 